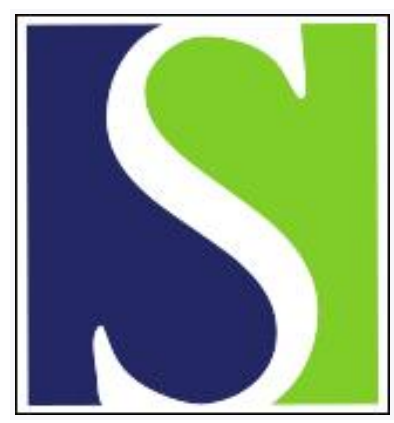

Scand J Work Environ Health 2002;28(2):75-84

https://doi.org/10.5271/sjweh.651

Issue date: Apr 2002

Effectiveness of physical activity programs at worksites with respect to work-related outcomes

by Proper KI, Staal BJ, Hildebrandt VH, van der Beek AJ, van Mechelen W

Affiliation: TNO Work and Employment, PO Box 718, NL-2139 AS Hoofddorp, Netherlands. K.Proper@arbeid.tno.nl

The following articles refer to this text: $2002 ; 28(2): 73-74$;

2004;30(1):36-46; 2008;34(1):55-65; 2010;36(3):202-215;

2013;39(1):66-75

Key terms: absenteeism; intervention study; physical activity program; physical fitness; review; review literature; systematic review; work-related outcome; workplace; worksite

This article in PubMed: www.ncbi.nlm.nih.gov/pubmed/12019591 


\title{
Effectiveness of physical activity programs at worksites with respect to work-related outcomes
}

\author{
by Karin I Proper, MSc, ${ }^{1,2,3}$ Bart J Staal, MSc, ${ }^{2}$ Vincent H Hildebrandt, PhD, 1,3 Allard J van der Beek, \\ $P h D, 2,3$ Willem van Mechelen, $M D^{2,3}$
}

\begin{abstract}
Proper KI, Staal BJ, Hildebrandt VH, van der Beek AJ, van Mechelen W. Effectiveness of physical activity programs at worksites with respect to work-related outcomes. Scand J Work Environ Health 2002;28(2):75-84.

This paper systematically reviews the literature on the effectiveness of physical activity programs at worksites with respect to work-related outcomes. A computerized literature search, a reference search, and a manual search of personal databases were performed using the following inclusion criteria: randomized controlled or controlled trial, working population, worksite intervention program to promote physical activity or physical fitness, and work-related outcomes. The study quality was evaluated using nine methodological criteria. Conclusions were based on a 5-level rating system of evidence. Eight studies ( 4 randomized controlled trials and 4 controlled trials) were identified, but their methodological quality was generally poor. The outcomes were absenteeism, job satisfaction, job stress, productivity, and employee turnover. The evidence of an effect was limited for absenteeism, inconclusive for job satisfaction, job stress and employee turnover, and nil for productivity. The scientific evidence on the effectiveness of physical activity programs at worksites is still limited. Because of the few highquality randomized controlled trials, it is strongly suggested that this type of study be carried out. Future randomized controlled trials should pay special attention to the description of randomization, inclusion criteria, compliance, and analyses according to intention to treat.
\end{abstract}

Key terms absenteeism, intervention studies, physical fitness, review literature, systematic review, workplace.

Despite the promotion of a more physically active lifestyle, only a minority of adults is engaged in physical activity at a level sufficient to maintain or increase fitness and health $(1,2)$. Because regular physical activity is associated with a decrease in risk factors for several chronic diseases (3-7), encouraging people to be (more) physically active is of major public health importance. In addition to the person-related benefits, employers may experience benefits from enhancing physical activity among their employees. Currently, corporations in western countries have become more and more aware of the importance of worksite programs aimed at increasing physical activity and fitness levels (8) and have offered such programs to their employees far more often during the past 20 years than before (9). Both in practice and in the literature, physical activity programs, physical fitness programs, and exercise programs have been used rather interchangeably. Such an interchange is in fact undesired because of the different meanings of the constructs physical activity, physical fitness and exercise. In order to reduce confusion regarding these different constructs, we have chosen arbitrarily to apply one single term in this article for all programs that describe physical activity, physical fitness, or exercise at worksites, namely, physical activity programs at worksites. Thus, in this paper, we consistently apply this term, which includes any one of the three types of programs mentioned.

According to Jex \& Heinisch (10), the primary rationale for implementing physical activity programs at worksites is that exercisers are healthier than nonexercisers, and therefore represent reduced health care costs

$1 \quad$ TNO Work and Employment, Hoofddorp, The Netherlands.

2 Department of Social Medicine, Institute for Research in Extramural Medicine, VU University Medical Centre, Amsterdam, The Netherlands.

3 Body@Work, Research Center Physical Activity, Work and Health, TNO-VU, The Netherlands.

Reprint requests to: Karin I Proper, TNO Work and Employment, PO Box 718, NL-2130 AS Hoofddorp, The Netherlands. [Email: K.Proper@arbeid.tno.nl] 
for the company. Dishman et al (9) supports this rationale by stating that physical activity programs at worksites are aimed at increasing productivity and at reducing health care costs. Many studies, and some reviews, have addressed the effectiveness of physical activity programs at worksites $(9,11-13)$. Two of these reviews $(11,13)$ described studies that investigated the impact of such interventions on both health-related and workrelated outcomes, but failed to evaluate the internal validity of the studies. Two other reviews $(9,12)$ examined the methodological quality of the studies included. However, both of these reviews focused on health-related outcomes only. In conclusion, no review was found that evaluated the effectiveness of worksite physical-activity programs on work-related outcomes while taking into account the methodological quality of each study. Therefore, the purpose of the our review was to assess the effectiveness of physical activity programs at worksites on work-related outcomes systematically by applying several methodological quality criteria and using a

Table 1. Criteria list for the methodological quality assessment of (randomized) controlled trials on the effectiveness of physical activity programs worksites and the definition of the criteria.

\begin{tabular}{|c|c|}
\hline Criterion & Definition \\
\hline $\begin{array}{l}\text { A Randomization } \\
\text { procedure }^{a}\end{array}$ & $\begin{array}{l}\text { Positive if a random (unpredictable) assignment } \\
\text { sequence of subjects to the study groups was } \\
\text { used and if there was a clear description of the } \\
\text { procedure and adequate performance of the } \\
\text { randomization }\end{array}$ \\
\hline $\begin{array}{l}\text { B Similarity of study } \\
\text { groups }\end{array}$ & $\begin{array}{l}\text { Positive if the study groups were similar at the } \\
\text { beginning of the study with regard to age and at } \\
\text { least one of the relevant outcome measures; if } \\
\text { differences existed between the groups, an } \\
\text { adjusted analysis had to be performed }\end{array}$ \\
\hline $\begin{array}{l}\text { C Inclusion or } \\
\text { exclusion criteria }\end{array}$ & $\begin{array}{l}\text { Positive if inclusion or exclusion criteria were } \\
\text { specified }\end{array}$ \\
\hline D Dropouts & $\begin{array}{l}\text { Positive if the percentage of dropouts during the } \\
\text { study period did not exceed } 20 \% \text { for short-term } \\
\text { follow-up ( } \leq 3 \text { months) or } 30 \% \text { for long-term } \\
\text { follow-up (>3 months) }\end{array}$ \\
\hline E Blinding & $\begin{array}{l}\text { Positive if the person performing the assess- } \\
\text { ments was blinded as to the assignment of } \\
\text { subjects to the groups or if objective instruments } \\
\text { were used; if questionnaires only were used, a } \\
\text { negative score was given }\end{array}$ \\
\hline F Compliance & $\begin{array}{l}\text { Positive if the participants attended at least } 75 \% \\
\text { of the prescribed frequency; if several adherent } \\
\text { groups were distinguished, the high-frequency } \\
\text { group had to attend at least } 75 \% \text { of the } \\
\text { prescribed frequency to score positively }\end{array}$ \\
\hline $\begin{array}{l}\text { G Intention-to-treat } \\
\text { analysis }\end{array}$ & $\begin{array}{l}\text { Positive if the intervention and reference subjects } \\
\text { were analyzed according to the group belonging } \\
\text { to their (initial) assignment, irrespective of } \\
\text { noncompliance and cointerventions }\end{array}$ \\
\hline $\begin{array}{l}\text { H Timing of outcome } \\
\text { assessments }\end{array}$ & $\begin{array}{l}\text { Positive if the timing of the outcome measure- } \\
\text { ment was identical for all the intervention and } \\
\text { reference groups and for all important outcome } \\
\text { assessments }\end{array}$ \\
\hline I Follow-up & Positive if follow-up was 6 months or longer \\
\hline
\end{tabular}

a Item A is only applicable for randomized controlled trials. rating system to determine the level of evidence as to effectiveness.

\section{Methods}

\section{Literature search}

The literature search included a computerized database search, a reference search, and a manual search in our personal database. The computerized literature search was conducted in Medline, Psychinfo, Sportdiscus, OSHrom, and Cisdoc. The key words used for the search were divided into four headings in accordance with the inclusion criteria given later in this paper. English, German, and Dutch publications from 1980 to 2000 were selected. Subsequently, the reference and manual search results were examined for additional studies. The inclusion criteria were (i) randomized controlled trial (RCT) or controlled trial (CT), (ii) working population, (iii) worksite program intended to increase physical activity or fitness; and (iv) work-related outcomes. Criteria for exclusion were (i) physical activity programs at worksites aimed at secondary prevention of specific health complaints and (ii) comprehensive worksite health program in which physical activity or fitness was merely one of the many program components.

\section{Methodological quality}

Two reviewers (KP and BS) independently evaluated the studies identified by means of a list containing methodological criteria (table 1). These criteria were derived from methodological guidelines for systematic reviews developed by the Cochrane Collaboration Back Review Group (14). As these guidelines were developed to review randomized controlled trials in the field of therapies and secondary prevention for back pain, some criteria had to be omitted or adjusted for the purpose of this particular review.

As the first criterion (randomization procedure) is not applicable to studies without the randomization of subjects, controlled trials could reach a maximal quality score of 8 rather than 9 . A positive score was given if there was a satisfactory description and adequate performance of each item concerned, according to the discretion of the reviewer. The reviewing process was planned so that a consensus meeting between the two reviewers would take place in order to solve disagreements, if such would arise. If no consensus could be reached during this meeting, a third reviewer should be consulted. Conclusions with regard to the effectiveness of physical activity programs at worksites on a certain outcome measure were drawn using a rating system as to levels of evidence. This rating system was based on 
several best-evidence syntheses applied in earlier comparable reviews (15-17). The following five levels of evidence were distinguished: (i) strong evidence: at least two randomized controlled trials of high quality with consistent results; (ii) moderate evidence: one randomized controlled trial of high quality and at least one randomized controlled trial of low quality or one randomized controlled trial of high quality and at least one controlled trial of high quality (for both situations, consistent results were required); (iii) limited evidence: one randomized controlled trial of high quality and at least one controlled trial of low quality or more than one randomized controlled trial of low quality or more than one controlled trial of high quality (for all situations, consistent results were required); (iv) inconclusive evidence: only one study or multiple controlled trials of low quality or contradictory results; and (v) no evidence: more than one study with the consistent result that no significant or relevant results were shown. A study was considered to be of high quality if more than $50 \%$ of the methodological criteria was scored positively. Otherwise, the study was considered to be of low quality. High and low quality are relative qualifications and have to be interpreted as relatively high and relatively low. The results of the studies were first examined for statistical significance. In case of no statistical significance, we checked whether the results were meaningful from an employer's perspective, defined as a $20 \%$ difference between study groups, in favor of physical activity programs at worksites (18). The results were considered to be consistent if at least $75 \%$ of the studies involved reported statistical significance or were meaningful as already defined. In this process, a hierarchical order of design and quality was used for the studies. For example, for strong evidence to be the conclusion, only results of the identified randomized controlled trials that were of high quality were taken into account and evaluated for consistency.

\section{Results}

The (computerized, reference, and manual) search identified 218 (193, 19, and 6, respectively) publications. Reading the title or abstracts or both resulted in the exclusion of 177 publications. After the whole text of the rest of the publications was read, another 20 (19-38) had to be excluded. Most of the studies were excluded because they did not involve a physical activity program at a worksite or did not evaluate the effect on work-related outcomes. In addition, nine studies were excluded because of a lack of a reference group (39-47). Finally, 12 publications were selected (48-59). Three publications concerned the same randomized trial $(52,56,57)$, and three others described one nonrandomized controlled trial $(49,50,58)$. For that reason, eight studies were evaluated (4 randomized controlled trials and 4 controlled trials). The two reviewers reached initial total agreement on $72 \%$ of the studies. Cohen's kappa was 0.45 for this initial agreement. Interpretation errors were the main reason for discrepancies between the two reviewers. After some discussion, the two reviewers could not reach agreement concerning item $\mathrm{C}$ (table 1) for four studies. As a result, a third reviewer $(\mathrm{VH})$ was consulted.

The quality scores ranged from 3 to 7 for the randomized controlled trials and from 1 to 5 for the controlled trials (table 2). Two of the randomized controlled trials $(51,53)$ and one of the controlled trials (59) were, according to our rating system, of high quality. For the randomized controlled trials, most of the shortcomings were due to unclear descriptions of the randomization procedure and the inclusion criteria. For the controlled trials, a lack of a sufficient description of the inclusion criteria, dropouts, or the level of compliance with the intervention were common shortcomings. Moreover, with the exception of one study (59), none of the trials had included an intention-to-treat analysis.

Table 2. Methodological quality of each study. (NA = not applicable)

\begin{tabular}{|c|c|c|c|c|c|c|c|c|c|c|}
\hline \multirow[t]{2}{*}{ Study } & \multicolumn{9}{|c|}{ Methodological quality criterion a } & \multirow[t]{2}{*}{ Total score } \\
\hline & $A$ & B & C & D & $E$ & $\mathrm{~F}$ & G & $\mathrm{H}$ & I & \\
\hline \multicolumn{11}{|l|}{ Randomized controlled trials } \\
\hline Kerr \& Vos, 1993 (53) & + & + & - & + & + & + & - & + & + & 7 \\
\hline Grønningsäter et al, 1992 (51) & - & + & + & + & - & + & - & + & + & 6 \\
\hline $\begin{array}{l}\text { Halfon et al, } 1994 \text { (52); Rosenfeld et al, } \\
1989 \text { (56); Rosenfeld et al, } 1990 \text { (57) }\end{array}$ & - & - & - & + & + & - & - & + & + & 4 \\
\hline Oden et al, $1989(55)$ & - & + & - & + & + & - & - & - & - & 3 \\
\hline \multicolumn{11}{|l|}{ Controlled trials } \\
\hline Skargren \& Öberg, 1999 (59) & NA & + & + & + & - & - & + & + & - & 5 \\
\hline $\begin{array}{l}\text { Cox et al, } 1981 \text { (49); Cox et al, } 1987 \text { (50); } \\
\text { Shephard et al, } 1981 \text { (58) }\end{array}$ & NA & + & - & - & + & - & - & + & + & 4 \\
\hline Blair et al, $1986(48)$ & NA & + & - & - & + & - & - & - & + & 3 \\
\hline Norris et al, 1990 (54) & NA & - & - & - & - & - & - & + & - & 1 \\
\hline
\end{tabular}

a See table 1 for the definitions of the criteria. 
Table 3. Detailed description of the randomized controlled trials and the controlled trials.

\begin{tabular}{|c|c|c|c|c|c|}
\hline Study & Intervention & $\begin{array}{l}\text { Posttest/ } \\
\text { follow-up }\end{array}$ & Study population & $\begin{array}{l}\text { Outcome measures and } \\
\text { their assessment }\end{array}$ & Results a \\
\hline
\end{tabular}

Randomized controlled trials

Grønningsäter et al, $\quad$ 1. Aerobic exercise aimed at im$1992(51)$

1. Aerobic exercise aimed at im-
proving physical capacity, strength, flexibility and relaxation; 10 weeks, 3 times per week, 55 minutes

2. Cognitive behavioral stress management, lectures, group discussions, self-study and home assignments; 10 weeks, 3 times per week, 55 minutes

3. Reference: no intervention

Halfon et al, 1994 (52); 1. Regular physical exercise, Rosenfeld et al, 1989 (56); Rosenfeld et al, $1990(57)$ stretching, relaxation, strength, aerobic exercises; 7 months, 5 times per week, 15 minutes

2. Reference: social games; 7 months, 5 times per week, 15 minutes
10 weeks and 6 months

171 insurance company workers (92 men, 79 women); age 25-67 years; 72 used for the analysis

7 months
12 months endurance, strength, flexibility, good body posture; 12 months, 1 time per week, 60 minutes

2. Reference: no intervention

Oden et al, 1989 (55) 1. Aerobics, walk or jog, bicycle ergometer, aerobic dance; 24 weeks, 3 times per week 2. Reference: no intervention

24 weeks

\section{Controlled trials}

Blair et al, 1986 (48)
152 bank workers (gender ?); mean age 37.6-39.4 years; 152 used for the analysis

45 blue-collar workers (9 men, 36 women): mean age 29.3 years (exercise group), 29.2 years (reference group); 45 used for the analysis satisfaction); 1 year (absenteeism)

12136 school district workers [79\% women men (nonparticipants)];
1. Weekly exercises and health education classes; 2 different program cycles of a 10-week intervention phase

2. Reference: participant group starting at a different time (participants), 78\% womean age 42.7 years (participants), 41.0 years (nonparticipants); 1835? used for the analysis (job satisfaction), 10806 used for the analysis (absenteeism)

Cox et al, 1981 (49); Cox et al, 1987 (50), Shephard et al, $1981(58)$
1. Rhythmic calisthenics, jogging, 3 and 6 months ball games, lectures; 6 months,

3 times per week, 30 minutes

2. Reference: no intervention
534 of 1858 insurance company workers completed all 3 physiological tests (234 men, 300
Norris et al, 1990 (54) 1. Aerobic training: road running; 10 weeks 10 weeks, 3 times per week, 45 minutes

2. Anaerobic training: weight training to improve muscular strength; 10 weeks, 3 times per week, 35 minutes

3. Reference: no intervention
522 pharmaceutical workers (255 men, 267 women); mean age 40 years; 461 ? used for the analysis
Job satisfaction: questionnaire asfaction:reward, relations with co-workers, resource adequacy, and promotions stress: 0 Job stress: questionnaire assessing stress related to workload, communication, relocation, and leadership

Absenteeism: (number of hours absent due to illness / total number of hours expected to work) $\times 100$

Job satisfaction: questionnaire Productivity: (i) self-reported work efficiency (workload/work fatigue) and (ii) objective self-efficiency / [(actual time needed to complete one defined unit $x$ the number of units produced)/net assigned worktime self-efficiency]

Absenteeism: absence time registered in bank records

Job satisfaction: questionnaire Job stress: questionnaire

Productivity: (i) net allowed hours number of hours allowed for work on the product hours + the unplanned labor hours such as rework and repair of a product) and (ii) quality yield (percentage of the product that passes inspection)

Absenteeism: computer tape data from the district personnel office women); mean age 30.2-40.1 years; 1858 used for the analysis (absenteeism), 481 used for the analysis (job satisfaction)

Absenteeism: collected for several months for several years

Job satisfaction: questionnaire assessing type of work, supervision, pay, opportunities for promotion, and co-workers

Productivity: average of quarterly departmental records Employee turnover: provided for individual departments along with an arbitrary assessment of productivity per department

150 police officers (all men); age 20-50 years: Job stress: questionnaire 77 used for the analysis eeism: +

Absenteeism: +

ob satisfaction: 0 Job stress: +

Productivity (i): 0 Producivity (ii): 0

Absent-

from

work: 0

Job satis-

Produc-

Produc-

vity (ii): 0

Absent-

eeism: + Job satis-

faction: 0

Produc-

tivity: 0

Employee

turn-

over: +

Job

stress: + 
Table 3. Continued.

\begin{tabular}{|c|c|c|c|c|c|}
\hline Study & Intervention & $\begin{array}{l}\text { Posttest/ } \\
\text { follow-up }\end{array}$ & Study population & $\begin{array}{l}\text { Outcome measures and } \\
\text { their assessment }\end{array}$ & Results a \\
\hline $\begin{array}{l}\text { Skargren \& Öberg, } \\
1999 \text { (59) }\end{array}$ & $\begin{array}{l}\text { 1. General strength and cardio- } \\
\text { vascular exercises; } 8 \text { weeks, } \\
2 \text { times per week, } 45 \text { minutes } \\
\text { per session } \\
\text { 2. Reference: no intervention }\end{array}$ & 8 weeks & $\begin{array}{l}106 \text { nurses and nursing } \\
\text { aides [84\% women (par- } \\
\text { ticipants), 86\% women } \\
\text { (nonparticipants), 88\% } \\
\text { women (referents)]; } \\
\text { mean age } 35.8 \text { years } \\
\text { (participants), } 37.7 \text { years } \\
\text { (nonparticipants), } 36.3 \\
\text { years (referents); } 78 \\
\text { used for the analysis }\end{array}$ & $\begin{array}{l}\text { Organizational or psychosocial work } \\
\text { conditions: questionnaire measuring } \\
\text { work climate, work content, work- } \\
\text { pace, demands on attention, work } \\
\text { planning, job security, job contraints, } \\
\text { and work-role ambiguity } \\
\text { Physical work conditions: ques- } \\
\text { tionnaire measuring heavy lifting, } \\
\text { demanding work positions, high } \\
\text { workpace, high demands on con- } \\
\text { centration and precision, and mainly } \\
\text { sitting }\end{array}$ & $\begin{array}{l}\text { Organiza- } \\
\text { tional or } \\
\text { psychoso- } \\
\text { cial work } \\
\text { condi- } \\
\text { tions: } 0 \\
\text { Physical } \\
\text { work } \\
\text { condi- } \\
\text { tions: } 0\end{array}$ \\
\hline
\end{tabular}

a 0 = no effect; + = positive effect; - = negative effect.

The outcome measures of the studies were absenteeism from work, job satisfaction, job stress, productivity, and employee turnover.

\section{Description of the studies}

A description of the characteristics of each study is given in table 3.

Type of intervention. Of the four randomized controlled trials, three involved a combined program of aerobic, strength, and flexibility exercises $(51-53,56,57)$. The other (55) focused on aerobic training only. Of the four controlled trials, the type of program differed somewhat. In the study reported by Cox et al $(49,50)$ and Shephard et al (58), the main focus was on the development of cardiorespiratory fitness, while in the study of Skargren \& Öberg (59) strength exercises were added to cardiovascular capacity exercises. In the study of Norris et al (54), two intervention programs were compared with a reference program, namely, an aerobic program and anaerobic program, which was aimed at improving muscle strength.

Study period. The study period of the four randomized controlled trials varied from 6 to 12 months, while that of the controlled trials lasted from 8 weeks to 1 year.

Study population. Both blue- and white-collar workers were investigated in the studies. Two of the randomized controlled trials evaluated the effect of physical activity programs at worksites using white-collar employees $(51,53)$, another randomized controlled trial used both white- and blue-collar employees $(52,56,57)$, while the study of Oden et al (55) investigated the effect using blue-collar subjects. Also, among the controlled trials, both blue- and white-collar employees were investigated. The types of employees studied in the controlled trials were employees working in insurance companies $(49,50,58)$, nursing staff (59), police officers (54) and school district employees (48).

\section{Absenteeism from work}

One high-quality randomized controlled trial (53), one low-quality randomized controlled trial (57), and two controlled trials $(48-50,58)$ were identified that evaluated the effect on absenteeism from work. The randomized controlled trial of high quality (53) and one controlled trial (48) showed a statistically significant positive effect of the program on absenteeism from work. In the study of Kerr \& Vos (53), both experimental groups showed a decrease in the frequency of absenteeism, while the frequency of absenteeism in the reference groups increased. The other randomized controlled trial (57) did not show a change during the study period. Furthermore, both controlled trials reported a positive influence of the intervention on absenteeism. On the basis of these findings, it was concluded that there is limited evidence for the effectiveness of worksite physical activity programs on absenteeism from work.

\section{Job satisfaction}

One randomized controlled trial of high quality (51), two randomized controlled trials of low quality $(52,55$, $57)$, and one low-quality controlled trial $(49,50,58)$ were identified that investigated the effect of physical activity programs at worksites on job satisfaction. The trial of high quality (51) reported a significant negative effect of the program on job satisfaction in that a decrease in job satisfaction was seen in the aerobic training group when it was compared with a stress management group and a reference group. In contrast, the study reported by Rosenfeld et al (57) and Halfon et al (52) showed a positive effect of physical activity training in that the reference group reported significantly lower jobsatisfaction scores than the workers engaged in a physical activity program at their worksites. The third randomized controlled trial (55) did not find a statistically significant change in job satisfaction for either group during the study period. Finally, the only controlled trial $(49,50,58)$ did not show a significant effect for the intervention. Thus it was concluded that there is 
inconclusive evidence for the effectiveness of physical activity programs at worksites on job satisfaction.

\section{Job stress}

One high-quality randomized controlled trial (51), one low-quality randomized controlled trial (55), and two controlled trials $(54,59)$ were identified that studied the effect of a physical activity program on job stress. The study of Grønningsäter et al (51) found no effect of the physical activity program on job stress. Although Oden et al (55) could not find statistically significant differences in job stress, differences between the experimental and reference groups were evaluated as meaningful. The study of Norris et al (54) showed significant improvements in self-reported measures of stress among the subjects participating in the aerobic and anaerobic training when compared with the reference group. In addition, the improvement of those engaged in aerobic training was greater than the effect of those engaged in anaerobic training. Finally, the study of Skargren \& Öberg (59), who evaluated the effect on organizational and psychosocial conditions and also physical work conditions, suggested that a physical activity program at work does not affect perceived work conditions, with one exception, namely, work planning. According to the results of the studies selected, we concluded that there was inconclusive evidence for an effect on job stress.

\section{Productivity}

Definitions of productivity in the studies included were (objective) self-efficiency, (perceived) work efficiency, quality yield, and net allowed hours. In addition, the method of measuring productivity differed among the studies in that some used subjective ratings $(52,56)$, while others used objective measures of productivity $(49,50,55,56,58)$. Rosenfeld et al (56) evaluated the effectiveness on both objective and subjective measures of productivity. Two randomized controlled trials (52, 55,56 ), both of low quality, evaluated the effect of a physical activity program at worksites on productivity. The study described by Halfon et al (52) and Rosenfeld et al (56) found significantly higher ratings of perceived work efficiency in the physical activity group than in the reference group. However, the objective measure of productivity, as reported by Rosenfeld et al (56), showed no change during the study period. The latter finding was supported by Oden et al (55), who also showed no statistically significant change in objectively measured productivity. The controlled study described by Cox et al $(49,50)$ and by Shephard et al $(58)$ also found no significant changes in productivity. Based on these find- ings, no evidence was found to indicate an effect of physical activity programs at worksites on productivity.

\section{Employee turnover}

Only one controlled trial was identified that had studied the effect on employee turnover (49). This study (49) showed that both high and low adherents had significantly less employee turnover than the nonparticipants. But, due to a lack of (randomized) controlled studies, inconclusive evidence was concluded for the effectiveness of physical activity programs at worksites on employee turnover.

\section{Discussion}

\section{Effectiveness}

The purpose of this systematic review was to gain insight into the effectiveness of physical activity programs at worksites on work-related outcomes. Despite the shortcomings of most of the trials, the outcomes suggest that there is limited evidence for the effectiveness of physical activity programs at worksites on absenteeism from work. For absenteeism, two randomized controlled trials were retrieved; one of high quality and one of low quality. The randomized controlled trial of high quality reported positive results, in contrast to the second randomized controlled trial identified, which was of low quality. As studies with lower methodological quality are supposed to have biased findings, we highly value the (positive) result of the one high-quality randomized controlled trial. Consequently, we believe that physical activity programs at worksites may offer relevant benefits for business and corporations regarding absenteeism from work. In addition, the difference in the study population and the intervention of the reference group between the two randomized controlled trials in question may explain the contradictory findings. The (high quality) trial that reported a positive effect on absenteeism from work used white-collar bank employees, while, in the (low quality) trial without positive outcomes, the majority of the subjects were laborers. As a larger gain can be obtained with subjects not being physically active, it is expected that white-collar workers, performing hardly any physical activities during work, show greater benefits than blue-collar workers do (60). The results of these two randomized controlled trials confirmed this dose-response relationship. Another explanation for the differences between the randomized controlled trials identified involves the program of the reference group. The trial that showed positive findings applied a reference group that did not take part in the 
fitness program and did not get any attention. In contrast, the study that did not find an effect used a reference group that received a social activity program and identical attention when compared with the physical activity group. This finding suggests a potential for a Hawthorne response, due to the less amount of attention the reference group received in comparison with the attention received by the intervention group.

We concluded that inconclusive evidence exists for the effect of physical activity programs at worksites on job satisfaction and job stress. Inconsistent results were the main reason behind this conclusion. In our opinion, the inconsistency of findings is largely due to variations in definition and the assessment of the outcomes or to the compliance with the program. With respect to the compliance, most of the studies failed to describe this aspect sufficiently so that we cannot determine the extent to which a positive effect can be expected for compliance. As the effectiveness of physical activity programs at worksites strongly depends upon compliance, future studies should pay attention to the description of the participation rate. Furthermore, it should be noted that most studies not having reported significant effects showed positive trends. It is noteworthy that $50 \%$ of the randomized controlled trials and the controlled trials used less than 100 subjects for their analyses, and therefore these studies may have lacked the statistical power needed to detect significant differences. Probably a larger sample would have resulted in significant effects.

With regard to productivity, different results were found between the studies evaluating the effectiveness on subjective and objective measures. The only randomized controlled trial examining the effect on perceived productivity showed a positive effect, whereas the same trial, plus another randomized controlled trial, could not find a change in favor of physical activity programs at worksites with respect to objectively measured productivity. These contradictory findings suggest that the experience of workers with regard to their productivity does not necessarily reflect what they, in fact, produce. Another plausible explanation for this contradiction may be that the subjects involved in the studies using objective measures were mainly blue-collar workers, whose productivity is determined by machinery instead of by worker control. Thus it may be that an increase in physical activity will lead indeed to feelings of improved efficiency, while in fact productivity rates remain constant because of machinery control.

Finally, inconclusive evidence was found for employee turnover, due to a lack of studies. Since a high employee turnover rate is very costly for the company, more high-quality research, preferably randomized controlled trials, should be conducted to determine whether physical activity programs at worksites prevent or reduce employee turnover.

\section{Limitations of the studies}

The methodological quality of the randomized controlled trials and the controlled trials included was poor overall. Most of the study shortcomings were due to a lack of, or unsatisfactory description of, randomization, intention-to-treat analysis, inclusion criteria, and compliance. It was stated in most studies that the employees were randomized into the intervention or reference group, without any mention of the randomization procedure or the person performing the randomization. As it remains unclear to the reader of these articles whether an adequate procedure was performed, bias may have existed (61). The randomization procedure was sufficiently described in only one study (53).

Another shortcoming included the compliance with the program, which in most cases was either described poorly or was found to be low according to our criteria.

Finally, with the exception of one controlled trial, none of the studies performed an intention-to-treat analysis. Absence of such an analysis may lead to bias since employees may drop out because of specific reasons that make them not comparable with the group that completes the study with respect to the outcome variables. Consequently, if dropouts are not taken into account, the effectiveness may be overestimated.

The aforementioned shortcomings are fully in line with the conclusions of Shephard (12), who reported that most of the studies he reviewed suffered from low methodological quality, like small and biased samples or lack of appropriate control observations. Most of the studies identified did not randomize their subjects into an intervention or reference group. Taking into consideration that the nonrandomized studies included in this review often compared participants and nonparticipants, without controlling for baseline differences, personality, and other differences between these groups should not be ignored when the results are explained $(11,62)$. Selfselection of participants into the intervention is a well known and very serious scientific shortcoming of nonrandomized studies evaluating the effects of physical activity programs at worksites. One should bear in mind, however, that employees who do not enjoy exercise, or who do not want to participate in a physical activity program at work, simply cannot be forced to do so.

\section{Limitations of the review}

As we excluded unpublished studies and abstracts, the possibility of publication bias cannot be ruled out. Small studies without significant differences in outcomes have a large chance of not being published $(63,64)$. Thus taking into account the fact that unpublished studies probably more often have negative results, there may be a danger of an overrepresentation of positive effects of physical activity programs at worksites in this review. 
However, since the (published) studies identified in the review could often not prove statistically significant differences or meaningful results from an employer's standpoint, we consider the possibility of such an overestimation of positive effects to be small.

Another problem that cannot be ruled out is the possibility that not all relevant publications were identified. However, this risk is probably small since we used different search strategies and several different bibliographical databases.

Moreover, in a systematic review, the possibility of bias due to a restriction in language may exist, as publications with significant results are more often published in English than in other languages $(63,65)$. Although we did not restrict this review to English-written studies only, the potential for such an overestimation of significant (positive) results still remains.

\section{Methodological quality assessment}

A meta-analysis (ie, the statistically pooling of data) may provide more conclusive evidence about the effectiveness of physical activity programs at worksites than a qualitative analysis. Nevertheless, we decided to carry out a qualitative analysis and to perform a best-evidence synthesis and refrain from conducting a metaanalysis for two reasons. First, the methodological quality of the studies reviewed was rather poor, and, second, these studies were very heterogeneous in terms of context, design, and subjects. Although the rating system we applied is arbitrary, it is considered to be a suitable method for distinguishing objectively between different study designs (randomized controlled trials versus controlled trials) and to assess the methodological quality of studies (relatively high versus relatively low) in a reproducible manner. For example, strong or moderate evidence can only be concluded for outcomes from randomized controlled trials of high quality. The cutoff points used for categorizing a study as a high-quality study and for concluding consistent results were chosen arbitrarily. Theoretically, other conclusions could have been drawn if we had applied other cut-off points. However, raising or lowering the cut-off point by $10 \%$ would not have led to more or fewer high-quality randomized controlled trials; therefore the same conclusions would have been drawn and the results from this review can be considered not to be sensitive to a change in these cut-off points. And also, with this methodology, our results agreed with those of other systematic reviews (16, 17).

In conclusion, there is limited evidence for the effectiveness of physical activity programs at worksites with respect to absenteeism from work and inconclusive evidence for effectiveness regarding job satisfaction, job stress, and employee turnover, and there is no evidence for effectiveness in respect to productivity. These conclusions are probably due to a lack of randomized controlled trials of high methodological quality. As many questions still remain unanswered, we strongly recommend that randomized controlled trials of high methodological quality be carried out on the effectiveness of physical activity programs at worksites with respect to work-related outcomes, although we realize that conducting such research in occupational settings is difficult.

\section{References}

1. Caspersen CJ, Merritt RK, Stephens T. International physical activity patterns: a methodological perspective. In: Dishman RK, editor. Advances in exercise adherence. Champaign: Human Kinetics, 1994:73-110.

2. U.S. Department of Health and Human Services. Physical activity and health: a report of the Surgeon General. Atlanta (GA): U.S. Department of Health and Human Services, Centers for Disease Control and Prevention, National Center for Chronic Disease Prevention and Health Promotion, 1996.

3. Stampfer MJ, Hu FB, Manson JE, Rimm EB, Willett WC. Primary prevention of coronary heart disease in women through diet and lifestyle. N Engl J Med 2000;343:16-22.

4. Lee IM, Sesso HD, Paffenberger RS. Physical activity and coronary heart disease risk in men - does the duration of exercise episodes predict risk? Circulation 2000;102:98196.

5. Ueji M, Ueno E, Osei-Hyiaman D, Takahashi H, Kano K. Physical activity and the risk of breast cancer: a case-control study of Japanese women. J Epidemiol 1998;8:116-22.

6. Cottreau CM, Ness RB, Kriska AM. Physical activity and reduced risk of ovarian cancer. Obstet Gynecol 2000;96:60914.

7. Bairati I, Larouche R, Meyer F, Moore L, Fradet Y. Lifetime occupational physical activity and incidental prostate cancer. Cancer Causes Control 2000;11:759-64.

8. Gebhardt DL, Crump CE. Employee fitness and wellness programs in the workplace. Am Psychol 1990;45:262-72.

9. Dishman RK, Oldenburg B, O'Neal H, Shephard RJ. Worksite physical activity interventions. Am J Prev Med 1998; 15:344-61.

10. Jex SM, Heinisch DA. Assessing the relationship between exercise and employee mental health: methodological concerns. In: Kerr J, Griffiths A, Cox T, editors. Workplace health, employee fitness and exercise. London: Taylor \& Francis, 1996:55-67.

11. Griffiths A. The benefits of employee exercise programmes [review]. Work Stress 1996;10:5-23.

12. Shephard RJ. Worksite fitness and exercise programs: a review of methodology and health impact. Am J Health Promot 1996;6:436-52.

13. Falkenberg LE. Employee fitness programs: their impact on the employee and the organization. Acad Manage Rev 1987; $12: 511-22$.

14. Van Tulder MW, Assendelft WJJ, Koes BW, Bouter LM. Method guidelines for systematic reviews in the cochrane collaboration back review group for spinal disorders. Spine 1997;22:2323-30. 
15. Van der Windt DAWM, Van der Heijden GJMG, Van den Berg SGM, Ter Riet G, De Winter AF, Bouter LM. Ultrasound therapy for musculoskeletal disorders: a systematic review. Pain 1999;81:257-71.

16. Van Poppel MN, Koes BW, Smid T, Bouter LM. A systematic review of controlled clinical trials on the prevention of back pain in industry. Occup Environ Med 1997;54:841-7.

17. Smidt N. Physiotherapy for lateral epicondylitis: a systematic review. In: Smidt N. Conservative treatments for tennis elbow in primary care [dissertation]. Amsterdam: Vrije University, 2001:13-45.

18. Goldsmith CH, Boers M, Bombardier C, Tugwell P. Criteria for clinically important changes in outcomes: development, scoring and evaluation of rheumatoid arthritis patients and trial profiles. J Rheumatol 1993;20:561-5.

19. Bertera RL. The effects of behavioral risks on absenteeism and health care costs in the workplace. J Occup Med 1991;33:1119-24.

20. Bertera RL. Behavioral risk factor and illness day changes with workplace health promotion: two-year results. Am J Health Promot 1993;7:365-73.

21. Bertera RL. The effects of workplace health promotion on absenteeism and employment costs in a large industrial population. Am J Public Health 1990;80:1101-5.

22. Conrad KM, Riedel JE, Gibbs JO. Effect of worksite health promotion programs on employee absenteeism. AAOHN J 1990;38:573-80.

23. Blair SN, Piserchia PV, Wilbur CS, Crowder JH. A public health intervention model for work-site health promotion. JAMA 1986;255:921-6.

24. Bly JL, Jones RC, Richardson JE. Impact of worksite health promotion on health care costs and utilization. JAMA 1986;256:3235-40.

25. Boutelle KN, Murray DM, Jeffery RW, Hennrikus DJ, Lando HA. Associations between exercise and health behaviors in a community sample of working adults. Prev Med 2000; 30:217-24.

26. Bowne DW, Russell ML, Morgan JL, Optenberg SA, Clarke AE. Reduced disability and health care costs in an industrial fitness program. J Occup Med 1984;26:809-16.

27. Breslow L, Fielding J, Herrman AA, Wilbur CS. Worksite health promotion: its evolution and the Johnson \& Johnson experience. Prev Med 1990;19:13-21.

28. Cady LD, Thomas PC, Karwasky RJ. Program for increasing health and physical fitness of fire fighters. J Occup Med $1985 ; 27: 110-4$.

29. Goodspeed RB, DeLucia AG. Stress reduction at the worksite: an evaluation of two methods. Am J Health Promot 1990;4:333-7.

30. Jones RC, Bly JL, Richardson JE. A study of a work site health promotion program and absenteeism. J Occup Med 1990;32:95-9.

31. Kronenfeld JJ, Jackson K, Blair SN, Davis K, Gimarc JD, Salisbury Z, et al. Evaluating health promotion: a longitudinal quasi-experimental design. Health Educ Q 1987;14:12339.

32. Okada K, Iseki T. Effects of a ten-year corporate fitness program on employees' health. In: Kaneko M, editor. Fitness for the aged, disabled, and industrial worker. Champaign: Human Kinetics, 1990:249-53.

33. Owen CA, Beard EF, Jackson AS, Prior BW. Longitudinal evaluation of an exercise prescription intervention program with periodic ergometric testing: a ten year appraisal. J Occup Med 1980;22:235-40.
34. Peterson M, Dunnagan T. Analysis of a worksite health promotion program's impact on job satisfaction. J Occup Environ Med 1998;40:973-9.

35. Petterson I-L, Arnetz BB. Psychosocial stressors and wellbeing in health care workers: the impact of an intervention program. Soc Sci Med 1990;47:1763-72.

36. Robison JI, Rogers MA, Carlson JJ, Mavis BE, Stachnik T, Stoffelmayr B, et al. Effects of a 6-month incentive-based exercise program on adherence and work capacity. Med Sci Sports Exerc 1992;24:85-93.

37. Wood EA, Olmstead GW, Craig JL. An evaluation of lifestyle risk factors and absenteeism after two years in a worksite health promotion program. Am J Health Promot 1989;4:128-33.

38. Yang M-C, Lairson DR, Frye N, Herd JA, Falck VT. The effects of wellness program attendance on physiologic measures, health practices and diet habits. Health Educ Research 1988;3:293-303.

39. Baun WB, Bernacki EJ, Tsai SP. A preliminary investigation: effect of a corporate fitness program on absenteeism and health care cost. J Occup Med 1986;28:18-23.

40. Bell BC, Blanke D. The effects of a worksite fitness program on employee absenteeism. Health Val 1989;13:3-11.

41. Bernacki EJ, Baun WB. The relationship of job performance to exercise adherence in a corporate fitness program. J Occup Med 1984;26:529-31.

42. Gettman LR. Cost/benefit analysis of a corporate fitness program. Fitness Bus 1986;August:1-17.

43. Leatt P, Hattin H, West C, Shephard RJ. Seven year followup of employee fitness program. Can J Public Health 1988; 79:20-5.

44. Lechner L, de Vries H, Adriaansen S, Drabbels L. Effects of an employee fitness program on reduced absenteeism. J Occup Environ Med 1997;39:827-31.

45. Leutzinger J, Blanke D. The effect of a corporate fitness program on perceived worker productivity. Health Val 1991; 15:20-9.

46. Lynch WD, Golaszewski TJ, Clearie AF, Snow D, Vickery DM. Impact of a facility-based corporate fitness program on the number of absence from work due to illness. J Occup Med 1990;32:9-13.

47. Tsai SP, Baun WB, Bernacki EJ. Relationship of employee turnover to exercise adherence in a corporate fitness program. J Occup Med 1987;29:572-5.

48. Blair SN, Smith M, Collingwood TR, Reynolds R, Prentice MC, Sterling CL. Health promotion for educators: impact on absenteeism. Prev Med 1986;15:166-75.

49. Cox M, Shephard RJ, Corey P. Influence of an employee fitness programme upon fitness, productivity and absenteeism. Ergonomics 1981;24:795-806.

50. Cox MH, Shephard RJ, Corey P. Physical activity and alienation in the workplace. J Sports Med 1987;27:429-36.

51. Grønningsäter H, Hytten K, Skauli G, CHristensen CC, Ursin $\mathrm{H}$. Improved health and coping by physical exercise or cognitive behavioral stress management training in a work environment. Psychol Health 1992;7:147-63.

52. Halfon ST, Rosenfeld O, Ruskin H, Tenenbaum, G. Daily physical activity program for industrial employees. In: Kaneko M, editor. Fitness for the aged, disabled, and industrial worker. Champaign: Human Kinetics, 1994:260-5.

53. Kerr JH, Vos MCH. Employee fitness programmes, absenteeism and general well-being. Work Stress 1993;7:179-90.

54. Norris R, Carroll D, Cochrane R. The effects of aerobic and anaerobic training on fitness, blood pressure, and 
psychological stress and well-being. J Psychosomatic Res 1990;34:367-75.

55. Oden G, Crouse SP, Reynolds C. Worker productivity, job satisfaction and work-related stress: the influence of an employee fitness program. Fitness Bus 1989 June:198-203.

56. Rosenfeld O, Tenenbaum G, Ruskin H, Halfon ST. The effect of physical training on objective and subjective measures of productivity and efficiency in industry. Ergonomics 1989;32:1019-28.

57. Rosenfeld O, Tenenbaum G, Ruskin H, Halfon ST. Behavioural modifications following a physical activity programme in the Israeli Pharmaceutical industry. Aust J Sci Med Sport 1990 Dec:93-6.

58. Shephard RJ, Cox M, Corey P. Fitness program participation: its effect on worker performance. J Occup Med 1981;23:359-63.

59. Skargren E, Öberg B. Effects of an exercise programme on organizational/psychosocial and physical work conditions, and psychosomatic symptoms. Scand J Rehabil Med 1999; 31:109-15.

60. Pate RR, Pratt M, Blair SN, Haskell WL, Macera CA, Bouchard $\mathrm{C}$, et al. Physical activity and public health, a recom- mendation from the Centers for Disease Control and Prevention and the American College of Sports Medicine. JAMA 1995;273:402-7.

61. Schulz KF, Chalmers I, Hayes RJ, Altman DG. Empirical evidence of bias: dimensions of methodological quality associated with estimates of treatment effects in controlled trials. JAMA 1995;273:408-12.

62. Eakin JM, Gotay CC, Rademaker AW, Cowell JW. Factors associated with enrollment in an employee fitness center. J Occup Med 1988;30:633-7.

63. Egger M, Smith GD. Bias in location and selection of studies. BMJ 1998;316:61-6.

64. Scherer RW, Dickersin K, Langenberg P. Full publication of results initially presented in abstracts. A meta-analysis. JAMA 1994;272:158-62.

65. Egger M, Zellweger-Zahner T, Schneider M, Junker C, Lengeler C, Antes G. Language bias in randomised controlled trials published in English and German. Lancet 1997; 350:326-9.

Received for publication: 14 June 2001 